\title{
EXPERIMENTAL RESEARCH INTO AERODYNAMIC PARAMETERS OF A CYLINDRICAL ONE-LEVEL 8-CHANNEL CYCLONE
}

\author{
Žilvinas VENCKUS, Albertas VENSLOVAS, Mantas PRANSKEVIČIUS \\ Institute of Environmental Protection, Vilnius Gediminas Technical University, \\ Sauletekio al. 11, LT-10223 Vilnius, Lithuania
}

Submitted 02 Jun. 2014; accepted 02 Oct. 2014

\begin{abstract}
The Environmental Protection Laboratory of Vilnius Gediminas Technical University has developed and installed a one-level 8-channel cyclone with different internal structure, which is used for separation of particulate matter from air streams. Airflow velocity was measured in five points of each channel: at the end and the beginning of the channel, in the middle of the channel and in points arranged at $45^{\circ}$ angle from the channel's end and beginning. The highest airflow velocity determined in 8-channel device by regulating volumes of peripheral and transit airflows with curvilinear semi-rings was in cyclone's channel 1, while the lowest - in channel 2. Contrary to the above, the highest airflow velocity in 8 -channel cyclone by using quarter-rings without holes and with $5^{\circ}$ opening angle of plates in holes was recorded in channel 2. Tests on aerodynamic resistance were carried out in airflow inlet and outlet ducts. In all cases analysed the highest aerodynamic resistance in 8-channel cyclone was determined when airflow distribution was regulated at 75/25 ratio with semi-rings. When quarter-rings without holes and with $5^{\circ}$ opening angle of plates in holes were used, higher aerodynamic resistance in the system was created by using quarter-rings without holes, i.e. $0^{\circ}$ opening of plates.
\end{abstract}

Keywords: cyclone, semi-ring, quarter-ring, airflow, particulate matter, air cleaning.

\section{Introduction}

The database of patents on devices for dust removal from an air (gas) mixture is expanding. A new generation of structural devices can remove increasingly smaller particulate matter from an ambient air. All inventions have a common goal - to achieve a higher degree of separating particulate matter of $10 \mu \mathrm{m}$ and smaller dispersion (Baltrènas et al. 2012; Pushnov, Berengarten 2011).

Cyclones are widely applied due to their simple structure, reliable operation as well as low capital and operating costs. Cyclone type airflow cleaners are widely used to dry-clean polluted gas emitted during the certain technological processes (dehumidification, burning, agglomeration, fuel combustion, etc). There is a wide variety of cyclones. By air stream direction cyclones are divided into reverse stream and straight stream systems, by form they are classified as conical and cylindrical, and by air flow direction (clockwise and anticlockwise) - right and left cyclones (Altmeyer et al. 2004; Bernardo et al. 2006; Elsayed, Lacor 2010; Vaitiekūnas, Jakštonienè 2010).

The cyclone structure has four main elements: inlet, shell, hopper and outlet. Cyclones have no moving parts, and particulates are separated from gas streams by the inertial force which is created by the gas flow rotating inside the device (this force is often referred to as the centrifugal force). Since during the cleaning process particulates are affected by gravitational and frictional forces, an increasing number of tests is carried out on the influence of geometrical and operational parameters on the optimum performance of cyclones (Elsayed, Lacor 2011; Hu et al. 2005; Gujun et al. 2008).

Scientific papers emphasise that the cyclone's cleaning efficiency depends on a number of factors such as properties of particulates (size, density), the flow rate of gas in the cyclone, geometrical parameters of the cyclone and also the time of gas residence in the cyclone. For example, centrifugal forces increase when a cyclone diameter is smaller and therefore narrower cyclones achieve higher efficiency; gas residence time is longer in cyclones whose cylindrical and conical parts are longer than the diameter and therefore the cleaning efficiency of such cyclones is higher or increases when the gas rate increases in the cyclone. To achieve the gas rotation rate, different inlets are used: tangential, continual, helical or axial (of

Corresponding author: Žilvinas Venckus

E-mail: zilvinas.venckus@vgtu.lt 
them, the most frequently used are tangential and continual inlet) (Burov et al. 2005, 2007; Gimbun et al. 2005; Kaya, Karagoz 2008; Veriankaitè et al. 2011).

Most scientific research concerns improvements to the structural elements of a cyclone inlet and outlet and the formation of swirling flows. Many experiments were carried out by reducing parameters of the cyclone shell, and also devices with a closed-loop system are created. The basis of such devices - curvilinear channels formed with semi-rings inside the device which create closed-loop systems. Loops of cylindrical shape have different diameters and are located at the angle $\varphi=\pi$, i.e. they are made of two walls of rings having different diameters. Each pair of adjacent channels forms one closed loop. Dust-polluted gaseous stream is filtered through a few layers, as particles circulate in closed loops due to the combination of dustpolluted stream filtering and centrifugal cleaning (Burov et al. 2011; Jakštonienè et al. 2011; Serebrensky 2011).

Scientific research has shown that theoretical relationships between particulate matter separation and the number of semi-rings in the cyclone can be approximately determined using formula 1 :

$$
\eta=1-\frac{1}{1+2^{n-1}}
$$

where $n$ - the number of semi-rings in multichannel cyclone, $\eta$ - particulate matter separation coefficient (Burov et al. 2005; Serebrensky 2004).

One of the main technical requirements is to achieve the highest possible air cleaning efficiency by reducing aerodynamic resistance in the device in order to minimise the amount of energy necessary for cleaning larger amounts of passing airflows. Aerodynamic resistance of the device is influenced by the flow rate and pressure loss. Pressure loss $(\Delta p)$ is directly dependent on losses generating at the time of gas entry into cyclone $\left(\Delta p_{i n}\right)$, losses generating inside the device $\left(\Delta p_{c}\right)$ and losses generating at the time gas leaves the cyclone $\left(\Delta p_{\text {out }}\right)$. The aforementioned losses in a multichannel cyclone can be theoretically described by the following relationship:

$$
\Delta p=\underbrace{\left(1-\frac{S_{1}}{S_{2}}\right)^{2} \frac{v_{\text {in }}^{2} \rho}{2}}_{\Delta p_{\text {in }}}+\underbrace{\frac{4 f l v^{2}}{2 D_{h}}}_{\Delta p_{c}}+\underbrace{0,5\left(1-\frac{S_{3}}{S_{4}}\right)^{2} \frac{v_{\text {out }}^{2} \rho}{2}}_{\Delta p_{\text {out }}},
$$

where $v_{i n}$ - incoming flow velocity, $S_{1}$ - cross-section area of gas inflow, $S_{2}$ - cross-section area of multichannel cyclone's channel 1 at outflow, $v_{\text {out }}$ - outgoing flow velocity; $S_{3}-$ cross-section area of gas outflow, $S_{4}$ - cross-section area of the last channel at outlet, $D_{h}$ - device's hydraulic diameter, $l$ - flow distance, $f=\frac{0,341}{\sqrt[4]{\operatorname{Re}}}, \operatorname{Re}=\frac{v h \rho}{\mu}, h$ - height of cyclone's cylindrical part.

The aim of such improvements to cyclone structures is to find the optimum relationship between aerodynamic resistance, which depends on the airflow rate, and air cleaning efficiency.

The aim of this paper is to perform experimental tests on how different arrangement of semi-rings and quarter-rings in one-level cyclone's internal structure affects the distribution of airflow velocities and aerodynamic resistance in the device.

\section{Methodology}

The experimental laboratory stand was developed at the Environmental Protection Technology Laboratory of Vilnius Gediminas Technical University. The stand system comprises a centrifugal ventilator which creates airflow, a flow inlet duct $(\mathrm{D}=200 \mathrm{~mm})$, a flow cleaner, i.e. one-level 8 -channel cyclone, and a cleaned airflow outlet duct $(\mathrm{D}=$ $160 \mathrm{~mm}$ ) (Fig. 1).

Experimental tests on airflow rates were carried out in the air duct system in which test points were selected in a straight segment, a steady flow and inside the cyclone structure, in the special holes of $8 \mathrm{~mm}$ made in each channel in the cyclone's cover.

Polluted air travels to the cyclone's diffuser from the inlet duct, while the separated particulate matter enters the double hopper via segment circular slits, and cleaned air is released through the outlet duct. The values of airflow resistance in holes made in the cyclone's cover measured with a dynamic Pitot tube and multifunctional meter Testo-400 were recalculated into airflow rates.

Instruments used during the experiment:

1. Dynamic Pitot tube;

2. Multifunctional meter Testo-400;

3. Accessory Testo 0638.1445;

4. Rubber hoses;

5. Vane anemometer;

6 . Aspirator, air suction rate error $\pm 6 \%$;

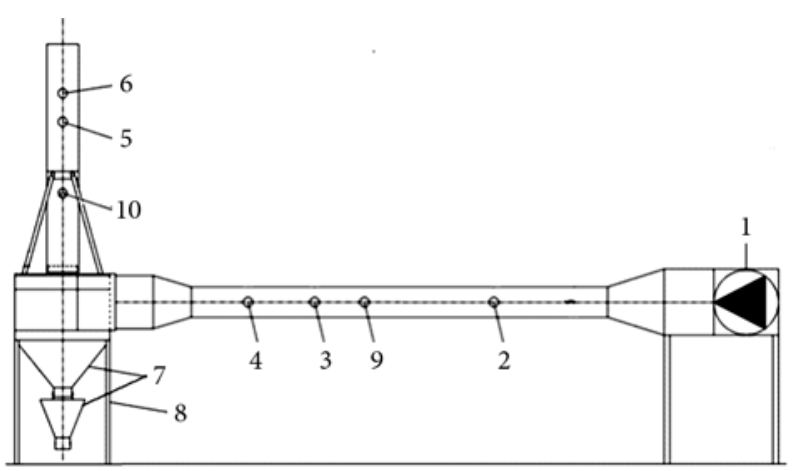

Fig. 1. Experimental stand for one-level 8-channel cyclone: 1 - centrifugal ventilator; 2 - particulates inlet; 3 - place for particulate matter concentration suction before cleaning; 4 - airflow rate measuring place in the inlet duct; 5 - place for particulate matter concentration suction after cleaning; 6 - airflow rate measuring place in the outlet duct; 7 - double hopper; 8 - bearing structure; 9,10 - nozzles for measuring resistance created by the system 
7. Electronic laboratory scale AG-204; graduation value $0.1 \mathrm{mg}$;

8. Filter holders;

9. Filters AFA-VP-20;

10. Pollutant feed sprayer;

11. Differential pressure meter DSM-1.

Airflow velocities in the device are evaluated taking into account different air flow rates created by the ventilator by changing air amounts in the ventilator control unit.

Devices of three different types were investigated by changing the type of the internal structure of one-level cyclone (see Fig. 2):

- eight-channel cyclone by making channels of different diameter and volume using quarter-rings without holes;

- eight-channel cyclone by making channels of different diameter and volume using quarter-rings having $5^{\circ}$ opening angle of plates in holes;

- eight-channel cyclone by making channels in it using semi-rings.

Airflow rate was measured in five points of each channel: at the end and beginning of the channel, in the middle of the channel and at points arranged at $45^{\circ}$ angle from the channel's end and beginning.
The airflow that enters and leaves each channel can be regulated by changing distances between semi-rings or quarter-rings of different diameter. As Figure 3 shows, three different positions of regulation were selected: a) peripheral (reciprocating) airflow volume equal to transit flow volume (moving to the next channel) (position $50 / 50)$; b) peripheral airflow volume by $50 \%$ larger than transit airflow volume (position 75/25); c) peripheral airflow volume by $50 \%$ smaller than transit airflow volume (position 25/75).

In order to avoid systematic mistakes and minimise the average error, three measurements were made in each measuring point.

Velocities in air ducts upstream and downstream the cyclone were measured by a vane anemometer and meter Testo-400. Due to improvements to the device structure the airflow velocity was measured with an anemometer in inlet and outlet ducts only. According to the measured velocities, airflow continuity and the exact amount of air entering the cyclone are determined. Measurements in the air duct were carried out in accordance with Lithuanian standard LAND 27-98/M-07 Measurement of gas flow velocity and volume rate in the air duct (1998).

To measure system resistance, special branch pipes, $7 \mathrm{~mm}$ in inner diameter and $10 \mathrm{~mm}$ in outer diameter,
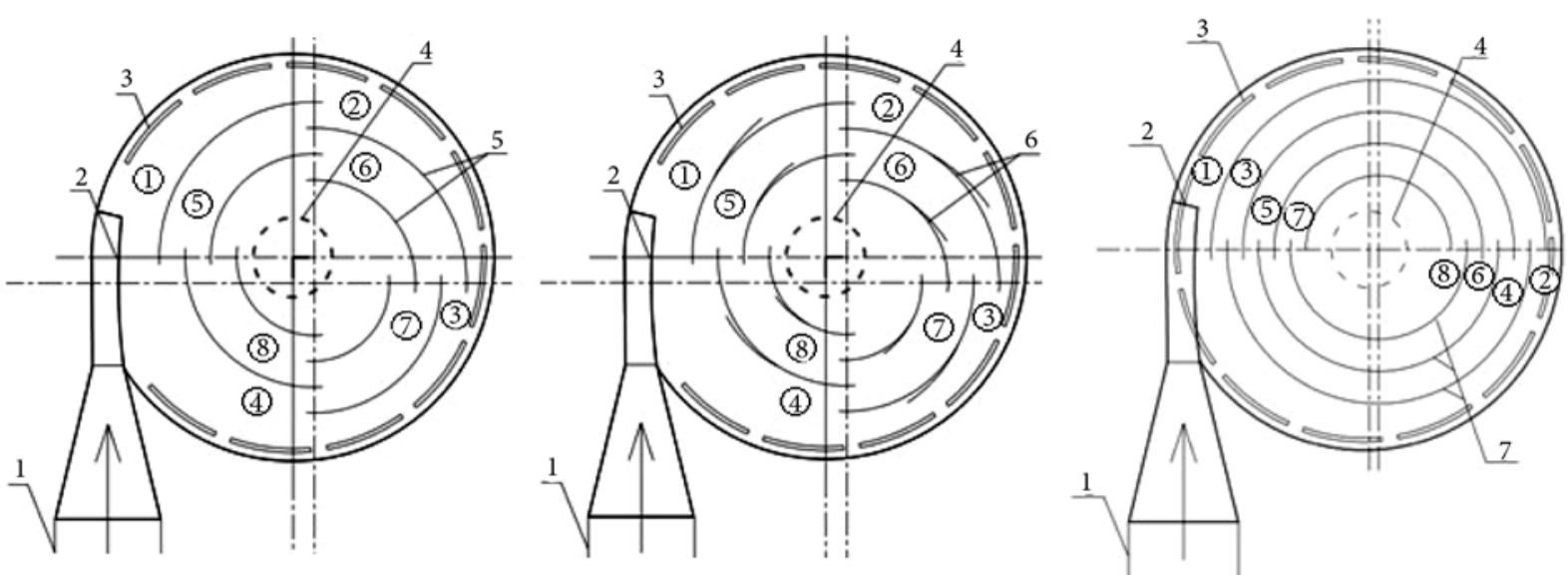

Fig. 2. Diagram of the internal structure of one-level 8-channel cyclone: 1 - polluted airflow supply duct, 2 - airflow inlet, 3 - segment circular slits, 4 - cleaned airflow outlet, 5 - curvilinear quarter-rings of different radius, 6 - opened plates, 7 - curvilinear semi-rings; $1-8$ - sequential number of the channel

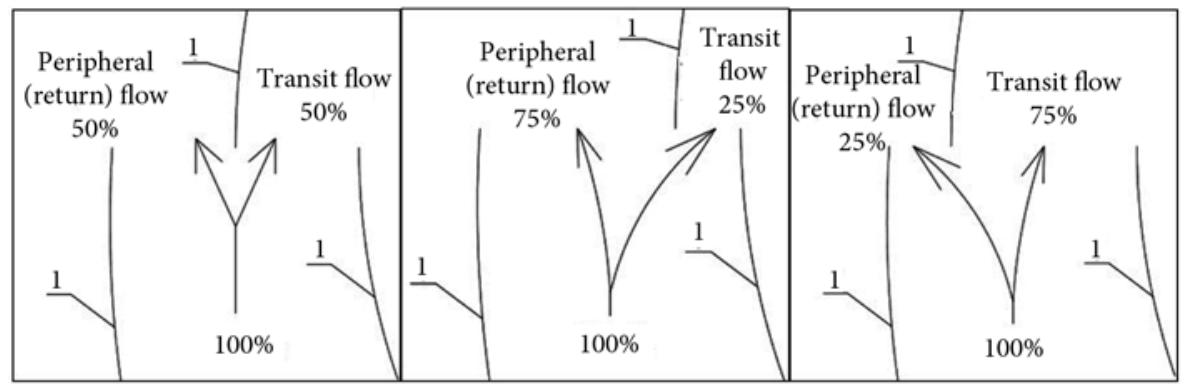

a)

b)

c)

Fig. 3. Diagrams of flow distribution ratios in a one-level multichannel cyclone: a) 50/50\%; b) $75 / 25 \%$; c) $25 / 75 \%$ 
were mounted in the air ducts of the experimental stand and hoses were connected to them for pressure measurement with the differential pressure meter DSM-1 (measuring range $0-20000 \mathrm{kPa}$; error $\pm 5 \mathrm{~Pa}$ ).

Aerodynamic pressure shows the value of the sum of dynamic and static pressure. During the tests one hose was connected to the branch pipe upstream the air purifier and the other - downstream the purifier.

\section{Results and their analysis}

During the tests on flow rates in 8-channel device incoming and outgoing flows were regulated by curvilinear semi-rings, and also by using solid quarter-rings and quarter-rings with $5^{\circ}$ opening angle of plates in holes. Tests were performed at an average flow rate in the cyclone of $16 \mathrm{~m} / \mathrm{s}$.

The results of tests on flow rates in 8-channel device obtained by regulating incoming and outgoing airflows with cylindrical curvilinear semi-rings are presented in Figure 4.

When transit and peripheral flows were regulated with semi-rings, a significant change in flow velocity was recorded in channel 1 of the cyclone. The highest value of airflow velocity was determined in the last measuring point of channel 1 in all semi-ring arrangement positions. When semi-rings are positioned so that the transit airflow is by $25 \%$ bigger than the peripheral flow (25/75 air volume distribution ratio), airflow rate reaches $20.0 \mathrm{~m} / \mathrm{s}$. When the volume of peripheral (reciprocating) airflow is equal to that of the transit airflow (moving to the next channels) (50/50 ratio), the measured flow rate reaches $23.6 \mathrm{~ms} / \mathrm{s}$. When semi-rings are arranged so that the peripheral air flow volume is $50 \%$ larger than the transit (75/25 ratio), the determined flow rate is $25.2 \mathrm{~m} / \mathrm{s}$. Velocity increases as a result of changing channel geometry, i.e. channel 1 is wider at the beginning of flow entry into cyclone than at the end of the cyclone and the flow rate increases when a uniform volume of passing airflow is maintained.

The lowest flow rate was determined in channel 2 . Cylindrical curvilinear semi-rings in a cylindrically-shaped cyclone are arranged in the descending order of radii and due to such arrangement the highest volume is in channel 2 resulting in velocity change of up to $18.9-21.2 \%$, compared to velocity recorded in channel 1 . From channel 3, velocity gradually decreases by $3-5 \%$ in every channel from the beginning of the channel towards its end. Since each channel width remains stable, the passing airflow is uniform and is affected by aerodynamic resistance. This means that velocity decreases under the impact of aerodynamic resistance and frictional force, as the airflow evens up while moving and is in constant contact with the channel walls.
The results of airflow velocity distribution determined in one-level 8-channel cyclone using solid quarterrings are presented in Figure 5.

In all cases analysed the highest airflow velocity was determined in the last measuring point of channel 2. Velocity determined in the aforementioned test point reaches $24.8-30.9 \mathrm{~m} / \mathrm{s}$. Velocity increases due to the fact that cylindrical curvilinear quarter-rings mounted in the cylindrically-shaped cyclone are arranged in the descending order of radii and are regulated considering the inlet width. Due to such arrangement quarter-ring 2 is moved up closer to the channel wall and the channel's volume suddenly drops at the end of channel 2.

Velocity in channels 1 and 3 increases in a similar way. Due to the structural arrangement the channels narrow and airflow velocity increases at the end of the channels respectively.

Velocity decreases in each channel starting from channel 4. A change in the average velocity in channel 4 and channel 5 reaches $2.8-3.8 \mathrm{~m} / \mathrm{s}$, and in channels 5 and $6-0.5-0.7 \mathrm{~m} / \mathrm{s}$. The tendency of decrease in

a)

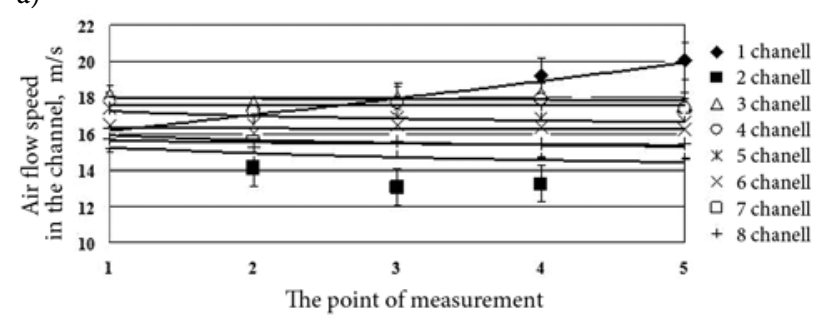

b)

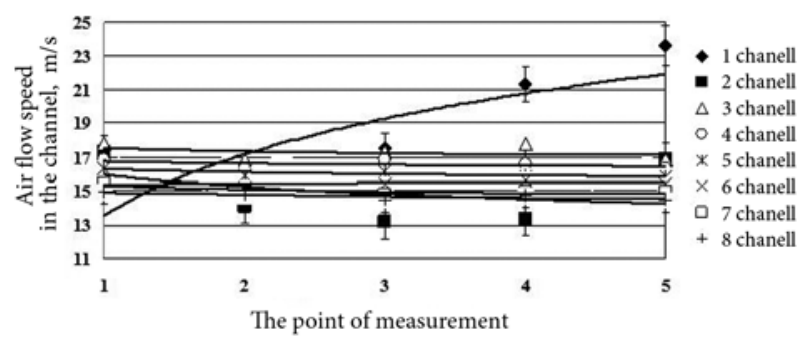

c)

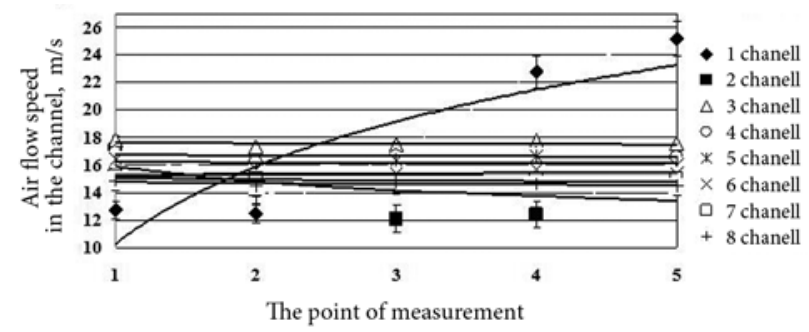

Fig. 4. Distribution of airflow velocities in 8-channel cyclone when air flows are regulated by curvilinear semi-rings: a) peripheral airflow volume is by $50 \%$ smaller than transit airflow volume (25/75); b) peripheral airflow volume is equal to transit airflow volume (50/50 position); c) peripheral airflow volume is by $50 \%$ larger than transit air volume

(75/25 position) 
subsequent channels remains similar. From channel 4, the channel width does not change in any channel and therefore the moving airflow is affected only by aerodynamic resistance, which results in decreasing velocity.

The relationship between airflow velocity distribution and airflow ratios in one-level 8-channel cyclone by using quarter-rings with $5^{\circ}$ opening of plates in holes is presented in Figure 6.

In all cases analysed the highest airflow velocity was determined in the last measuring point of channel 2 by regulating the internal position of quarter-rings. When flows are affected by $25 / 75$ position, the determined velocity reaches $25.2 \mathrm{~m} / \mathrm{s}$, in case of $50 / 50$ position $-28.1 \mathrm{~m} / \mathrm{s}$ and $75 / 25-31.9 \mathrm{~m} / \mathrm{s}$.

Velocity continually falls in each channel starting from channel 4 . The determined change in the average velocity in channel 4 and channel 5 reaches $3.4-3.8 \mathrm{~m} / \mathrm{s}$, and in channels 5 and $6-0.7-0.8 \mathrm{~m} / \mathrm{s}$. The tendency of decrease in subsequent channels remains similar. From channel 4 , the channel width remains steady in each channel and therefore the passing airflow is uniform and is affected

a)

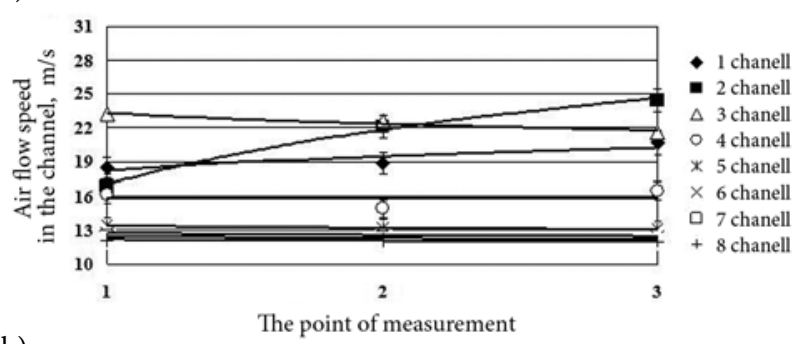

b)

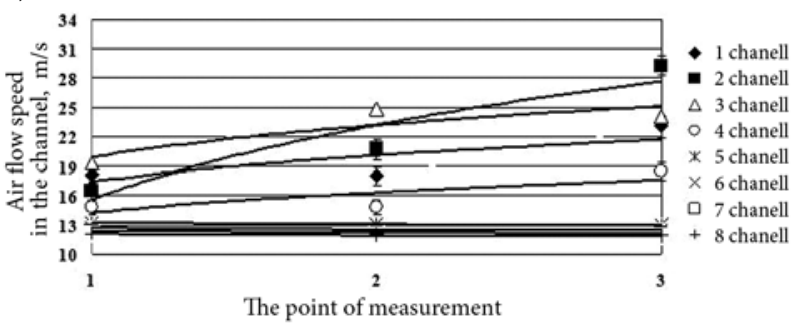

c)

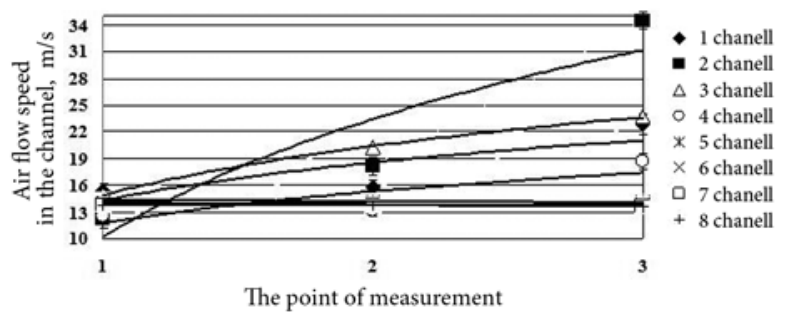

Fig. 5. Distribution of airflow velocities in 8-channel cyclone's channels when solid quarter-rings are used: a) peripheral airflow volume is by $50 \%$ smaller than transit airflow volume (25/75); b) peripheral airflow volume is equal to transit airflow volume (50/50 position); b) peripheral airflow volume is by $50 \%$ larger than transit air volume (75/25 position) only by aerodynamic resistance, i.e. velocity decreases under the impact of aerodynamic resistance.

In channels 5 to 8 velocity decreases from the beginning towards the end of the channel, the decrease reaches $1-6 \%$. The biggest decrease in velocity, $3-7 \%$, was in channel 5. The longer the airflow travels within a channel the higher the impact of frictional force on the flow and therefore a bigger drop in velocity was recorded in channel 5 whose width remains even.

A comparison of data has shown that after making holes with $5^{\circ}$ opening angle of their plates in quarter-rings, airflow velocity in channels 1 to 4 rose by up to $1 \mathrm{~m} / \mathrm{s}$, while in internal channels (channels 5 to 8 ) respectively fell (up to 7\%). Due to the holes with plates opened at $5^{\circ}$ angle, part of the airflow is additionally returned and therefore velocity in external channels increases.

Figure 7 shows the aerodynamic resistance values of 8-channel cyclone when the peripheral to transit airflow ratio is regulated with curvilinear semi-rings.

Aerodynamic resistance in 8-channel cyclone was investigated at an average airflow velocity of $16 \mathrm{~m} / \mathrm{s}$. The

a)

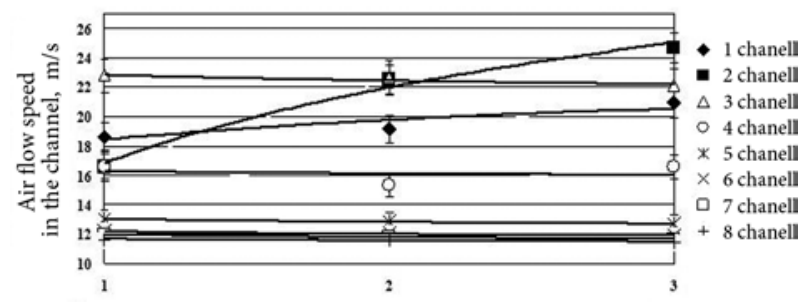

b)

The point of measurement

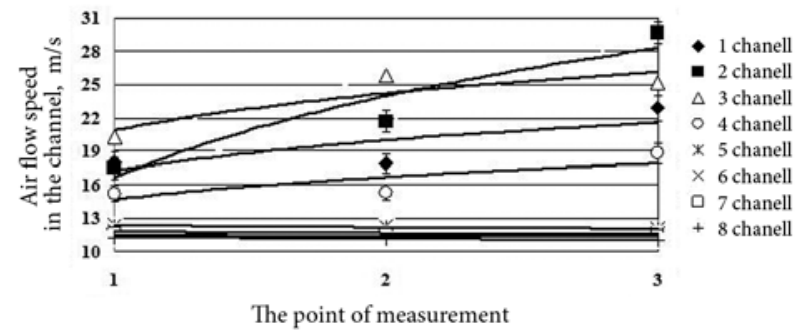

c)

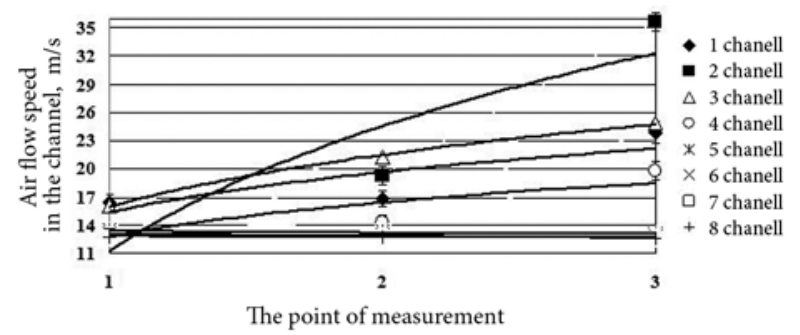

Fig. 6. Distribution of airflow velocities in 8-channel cyclone's channels when quarter-rings with $5^{\circ}$ opening angle of plates in holes are used: a) peripheral airflow volume is by $50 \%$ smaller than transit airflow volume (25/75); b) peripheral airflow volume is equal to transit airflow volume (50/50 position); c) peripheral airflow volume is by $50 \%$ larger than transit air volume (75/25 position) 
biggest aerodynamic resistance, $1605 \mathrm{~Pa}$, was determined when the airflow was regulated with curvilinear semirings at 75/25 distribution ratio. The smallest aerodynamic resistance, $1330 \mathrm{~Pa}$, was found when the airflow was distributed with semi-rings at $25 / 75$ ratio. The aerodynamic resistance obtained in 8-channel cyclone at even peripheral and transit airflow distribution (50/50) reaches $1550 \mathrm{~Pa}$. It can be assumed that due to the peripheral and transit airflow volume distribution ratio of $75 / 25$, a bigger part of the airflow is directed to the previous channel towards the device's periphery and therefore air flow pressure in the device's axis and outlet airflow duct increases.

Figure 8 presents the relationship between the aerodynamic resistance and airflow distribution ratio when the airflows in the 8-channel cyclone are regulated by quarter-rings without holes. It has been determined that the highest aerodynamic resistance at $16 \mathrm{~m} / \mathrm{s}$ average flow velocity is created at $75 / 25$ flow distribution ratio and reaches $1550 \mathrm{~Pa}$. It can be assumed that when a reciprocating flow is larger, the flow makes greater swirl movements in the cyclone's external channels than in the internal ones, which at the same time causes bigger losses of the flow energy resulting in an increase in aerodynamic resistance.

The smallest aerodynamic resistance was obtained when the peripheral and transit flows were distributed at $25 / 75$ ratio. This produces a reverse effect of flow movement within the cyclone's channels, i.e. a bigger part of the airflow enters internal channels, thus generating bigger velocity in the outgoing flow duct because of smaller flow energy losses.

The results of tests on aerodynamic resistance in the cyclone when quarter-rings with $5^{\circ}$ opening angle of plates in holes are used are presented in Figure 9.

While using quarter-rings with $5^{\circ}$ opening angle of plates in holes it has been determined that the values of aerodynamic resistance are lower compared to cases when semi-rings or solid quarter-rings were used. It can be stated that the holes in quarter-rings enable the airflow to move along a trajectory of lower resistance and return to the previous channel, i.e. fewer obstacles are created to the airflow movement. The aerodynamic resistance determined at 25/75 flow distribution ratio reaches $1330 \mathrm{~Pa}$, at 50/50 - 1370, 75/25 - 1450 Pa.

\section{Conclusions}

1. When peripheral and transit airflow volumes were regulated with semi-rings, the highest value of airflow velocity, $20.0-25.2 \mathrm{~m} / \mathrm{s}$, in an 8-channel air purifier was determined in the last measuring point of channel 1. Velocity increases due to a significant increase in the channel's geometry, i.e. channel 1 is wider at the beginning of flow entry into cyclone than at the end and flow velocity increases by maintaining a uniform volume of the passing airflow.

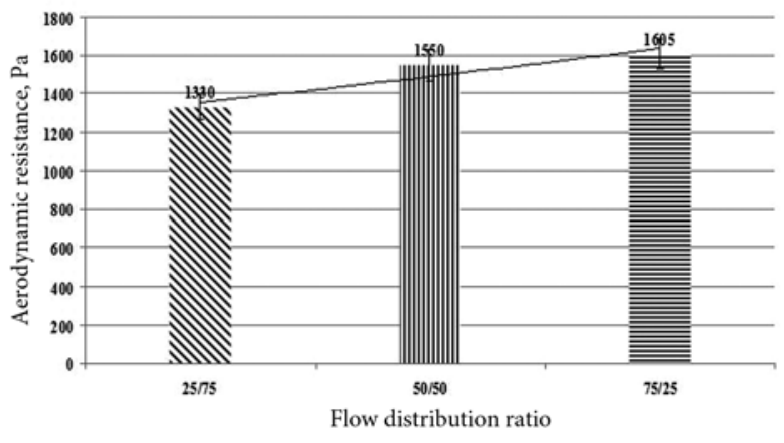

Fig. 7. Relationship between aerodynamic resistance and airflow distribution ratio in one-level cylindrical 8-channel cyclone by using curvilinear semi-rings

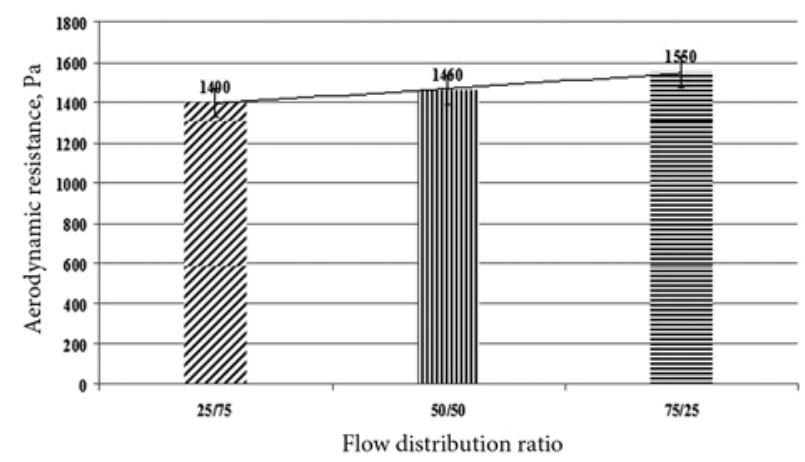

Fig. 8. Relationship between aerodynamic resistance and airflow distribution ratio in one-level 8-channel cyclone when quarter-rings without holes are used

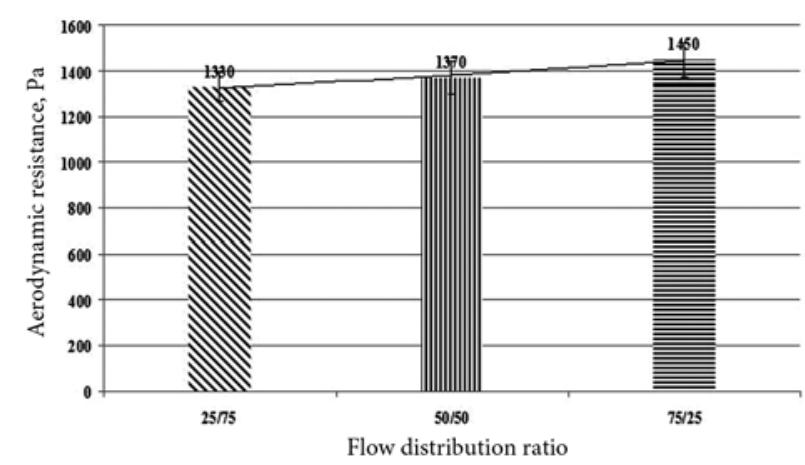

Fig. 9. Relationships between aerodynamic resistance and airflow distribution ratio in one-level 8-channel cyclone when quarter-rings with $5^{\circ}$ opening angle of plates in holes are used

2. When the peripheral and transit flows in the cyclone were regulated with semi-rings, the smallest values of airflow velocity were identified in channel 2 , as the channel's volume was the highest due to the arrangement of curvilinear semi-rings in the descending order of radii. Compared to velocity in channel 1 , velocity change accounts for up to $18.9-21.2 \%$. In channels 3 to 8 velocity decreases by $3-5 \%$ from the beginning towards the end of the channel. 
3. When quarter-rings without holes and with $5^{\circ}$ opening angle of plates in holes were used, the highest airflow velocity in 8-channel cyclone was determined in the last measuring point of channel 2 reaching $24.8-31.9 \mathrm{~m} / \mathrm{s}$. Velocity increases due to the quarter-ring arrangement leading to a sudden decrease in the channel's volume at the end of the last channel.

4. It has been noticed that after holes with $5^{\circ}$ opening angle of their plates were made in quarter-rings, airflow velocity in channels 1 to 4 rose by up to $1 \mathrm{~m} / \mathrm{s}$, while in internal channels (channels 5 to 8 ) respectively fell (up to $7 \%$ ). Due to the holes with plates opened at $5^{\circ}$ angle, part of the airflow is additionally returned and therefore velocity in external channels increases.

5. The biggest aerodynamic resistance, $1605 \mathrm{~Pa}$, was determined when the airflow was regulated with curvilinear semi-rings at $75 / 25$ distribution ratio. It can be assumed that due to the peripheral and transit airflow volume distribution ratio of $75 / 25$, a bigger part of the airflow is directed to the previous channel towards the device's periphery and therefore air flow pressure in the device's axis and outlet airflow duct increases. The smallest aerodynamic resistance, $1330 \mathrm{~Pa}$, was recorded when the airflow was distributed with semi-rings at $25 / 75$ ratio.

6. As regards the use of quarter-rings without holes and with $5^{\circ}$ opening angle of plates in holes, a bigger aerodynamic resistance of the system is achieved using quarter-rings without holes, i.e. $0^{\circ}$ opening of plates and, depending on a flow distribution ratio, reaches 1400 to $1550 \mathrm{~Pa}$. When quarter-rings with $5^{\circ}$ opening angle of plates in holes are used the resistance ranges between 1330 and $1450 \mathrm{~Pa}$. When holes are made, the reciprocating airflow increases and for this reason outgoing airflow velocity and aerodynamic resistance decrease.

\section{References}

Altmeyer, S.; Mathieu, V.; Jullemier, S.; Contal, P.; Midoux, N.; Rode, S.; Leclers, J. P. 2004. Comparision of different models of cyclone prediction performance for various operating conditions using a general software, Chemical Engineering and Processing 43: 511-522.

http://dx.doi.org/10.1016/S0255-2701(03)00079-5

Baltrènas, P.; Vaitiekūnas, P.; Jakštonienė, I.; Konoverskyte, S. 2012. Study of gas-solid flow in a multichannel cyclone, Journal of Environmental Engineering and Landscape Management 20(2): 129-137.

http://dx.doi.org/10.3846/16486897.2011.645825

Bernardo, S.; Mori, M.; Peres, A. P.; Dionisio, R. P. 2006. 3-D Computational fluid dynamics for gas and gas-particle flows in a cyclone with different inlet section angles, Powder Technology 162(3): 190-200.

http://dx.doi.org/10.1016/j.powtec.2005.11.007

Burov, A. A.; Burov, A. I.; Gamolič, V. A. 2007. Kontinualnaia model zapylennogo krivolineinogo techeniia gaza, Trudy Odesskogo politekhnicheskogo universiteta 1(27): 235-237. Odessa.
Burov, A. A.; Burov, A. I.; Silin, A. V.; Tcabiev, O. N. 2005. Tcentrobezhnaia ochistka promyshlennykh vybrosov v atmosferu, Ekologiia dovkillia ta bezpeka zhittediialnosti 6: 44-51.

Burov, A. A.; Burov, A. I.; Karamushko, A. V. 2011. Povitriana techiia u krivoliniinomu kanali, Ekologiia dovkillia ta bezpeka zhittediialnosti 12: 174-177.

Elsayed, K.; Lacor, C. 2010. Optimization of the cyclone separator geometry for minimum pressure drop using mathematical models and CFD simulations, Chemical Engineering Science 65(22): 6048-6058. http://dx.doi.org/10.1016/j.ces.2010.08.042

Elsayed, K.; Lacor, C. 2011. The effect of cyclone inlet dimensions on the flow pattern and performance, Applied Mathematical Modelling 35(4): 1952-1968. http://dx.doi.org/10.1016/j.apm.2010.11.007

Gujun, W.; Guogang, S.; Xiaohu, X.; Mingxian, S. 2008. Solids concentration simulation of different size particles in a cyclone separator, Powder Technology 183: 94-104. http://dx.doi.org/10.1016/j.powtec.2007.11.019

Gimbun, J.; Chuah, T. G.; Fakhru'l-Razi, A.; Choong, T. S. Y. 2005. The influence of temperature and inlet velocity on cyclone pressure drop: a CFD study, Chemical Engineering Progress 44: 7-12. http://dx.doi.org/10.1016/j.cep.2004.03.005

Hu, L. Y.; Zhou, L. X.; Zhang, J.; Shi, M. X. 2005. Studies on strongly swirling flows in the full space of volute cyclone separator, AlChE Journal 51(3): 740-749. http://dx.doi.org/10.1002/aic.10354

Jakštonienè, I.; Serebryansky, D. A.; Vaitiekūnas, P. 2011. Experimental research on the work of centrifugal filter when eliminating solid particles from clinker cooling system, in The 8th International Conference „Environmental Engineering": selected papers, 19-20 May 2011, Vilnius, Lithuania, vol. 1. Vilnius: Technika, 134-138. ISBN 978-9955-28-263-1.

Kaya, F.; Karagoz, I. 2008. Performance analysis of numerical schemes in highly swirling turbulent flows in cyclones, Current Science 94(10): 1273-1278.

LAND 27-98/M-07. 1998. Stacionarūs atmosferos teršalų šaltiniai. Duju srauto greičio ir tūrio debito ortakyje matavimas [online], [cited 09 October 2014]. Available from Internet: http:// www.litlex.lt/scripts/sarasas2.dll?Tekstas=1\&Id=28387

Pushnov, A.; Berengarten, M. 2011. Ecological aspects of industrial cooling towers exploitation and it's influence to environment, Journal of Environmental Engineering and Landscape Management 19(2): 158-166. http://dx.doi.org/10.3846/16486897.2011.583390

Serebrensky, D. A. 2004. Povyshenie effektivnosti gazoochistki teplovykh energeticheskikh ustanovok. Odesskii natcionalnyi politekhnicheskii universitet, Odessa. $155 \mathrm{c}$.

Serebrensky, D. A. 2011. Vysokoeffektivnyi tcentrobezhnyi filtr dlia ochistki gazov. Institut tekhnicheskoi teplofiziki Natcionalnoi akademii nauk Ukrainy, Kiev. 8 c.

Vaitiekūnas, P.; Jakštonienè, I. 2010. Analysis of numerical modelling of turbulence in a conical reverse-flow cyclone, Journal of Environmental Engineering and Landscape Management 18(4): 321-328. http://dx.doi.org/10.3846/jeelm.2010.37

Veriankaitè, L.; Šaulienè, I.; Bukantis, A. 2011. Evaluation of meteorological parameters influence upon pollen spread in the atmosphere, Journal of Environmental Engineering and Landscape Management 19(1): 5-11. http://dx.doi.org/10.3846/16486897.2011.557252 
Žilvinas VENCKUS. Junior Researcher, Dept of Institute of Environmental Protection, Vilnius Gediminas Technical University (VGTU). Master of Science (Environmental Engineering) Vilnius Gediminas Technical University (VGTU), Bachelor of Science (Environmental Engineering), ŠU, 2009. Research Interests: environmental protection, clean technology, environmental modeling.

Albertas VENSLOVAS. Dr (since 2014), Dept of Institute of Environmental Protection, Vilnius Gediminas Technical University (VGTU). Master of Science (Environmental Engineering), VGTU, 2008. Bachelor of Science (Environmental Engineering), LŽŪU, 2006. Research Interests: environmental protection, environmental modeling.

Mantas PRANSKEVIČIUS. Dr (since 2012), Dept of Institute of Environmental Protection, Vilnius Gediminas Technical University (VGTU). Master of Science (Environmental Engineering), VGTU, 2008. Bachelor of Science (Environmental Engineering), ŠU, 2006. Research Interests: environmental protection, environmental modelling, air pollution. 